\title{
Determination of Benzo[b]naphtho[2,3-d]thiophene (BNT) in Sediments using Selective Heavy Atom Induced Room-Temperature Phosphorimetry
}

\author{
Carlos Eduardo Cardoso and Ricardo Q. Aucélio* \\ Departamento de Química, Pontifícia Universidade Católica do Rio de Janeiro, 22453-900 Rio de Janeiro-RJ, Brazil
}

\begin{abstract}
As características fosforescentes do benzo[b]nafto[2,3-d]tiofeno (BNT) foram estudadas sob diferentes condições experimentais. Melhores resultados foram obtidos utilizando-se Tl(I) e $\mathrm{Pb}$ (II) como indutores de fosforescência, em ambos os casos usando dodecilsulfato de sódio (SDS) como modificador de superfície. Nestas duas condições, curvas analíticas de 3 ordens de magnitude forneceram limites de detecção e quantificação de respectivamente 0,6 e 2,0 ng na presença de $\mathrm{Tl}(\mathrm{I})$ e 3,2 e 10,7 ng na presença de $\mathrm{Pb}(\mathrm{II})$. A potencialidade da metodologia desenvolvida para determinação de BNT em nível de traços foi testada usando amostras de sedimento enriquecidas com o analito de interesse e $\mathrm{Pb}$ (II) como átomo pesado seletivo para indução de fosforescência. A recuperação de BNT foi bastante satisfatória $(101,5 \pm 7,4 \%, n=6)$ indicando que o método pode ser aplicado para a análise de amostras complexas. A interferência de outros hidrocarbonetos policíclicos aromáticos (pireno, criseno, carbazol, 7,9dimetilbenzo[c]acridina e dibenzotiofeno) foi avaliada e o método foi considerado seletivo na presença destas substâncias.
\end{abstract}

Room-temperature phosphorescence characteristics of benzo[b]naphtho[2,3-d]thiophene (BNT) were studied under several experimental conditions. Best phosphorescence was obtained using $\mathrm{Tl}(\mathrm{I})$ and $\mathrm{Pb}(\mathrm{II})$ as heavy atom enhancers, both in the presence of SDS as surface modifier. Under these two conditions of maximum phosphorescence, working curves with three orders of magnitude were achieved and absolute limits of detection and quantification of respectively 0.6 and $2.0 \mathrm{ng}$ in the presence of $\mathrm{Tl}(\mathrm{I})$ and 3.2 and $10.7 \mathrm{ng}$ in the presence of $\mathrm{Pb}(\mathrm{II})$. The RTP potential for selective trace-level determination was tested using a sediment sample spiked with BNT and using $\mathrm{Pb}(\mathrm{II})$ as the selective heavy atom enhancer. The recovery of BNT was very satisfactory $(101.5 \pm 7.4 \%, \mathrm{n}=6)$ indicating that the method can be properly applied for the analysis of complex samples. The interference potential from other polycyclic aromatic hidrocarbons (pyrene, chrysene, carbazole, 7,9-dimethylbenz[c]acridine and dibenzothiophene) was evaluated and the method was considered selective in the presence of these substances.

Keywords: benzo[b]naphtho[2,3-d]thiophene, heavy-atom induced phosphorescence, solid substrate, sediment

\section{Introduction}

Crude oils originate from the decomposition and transformation of aquatic, mainly marine, animals and plants that became buried under successive layers of mud and silt some 15-500 million years ago. They are very complex mixtures of different hydrocarbons. Depending on the source, the oils contain various amounts of straight and branched-chain paraffins, cycloparaffins, naphthenics, aromatics, sulphurated, nitrogenated and polycyclic aromatic hydrocarbons (PAH's). The sulfur content of crude oil is present not only as sulfide but also as

*e-mail: aucelior@rdc.puc-rio.br mercaptans, disulfides, sterically hindered dibenzothiophenes, thiophenes, and more complex organic sulfur compounds. ${ }^{1}$

The presence of sulfur compounds is undesirable in petroleum and in its derivatives. In recent years, the allowable sulfur levels in fuels have been drastically lowered by government regulations in order to reduce air pollution. ${ }^{2}$ Environmental protection and deep processing of petroleum products demand further reduction of the sulfur content of heavy fractions. Some sulfur compounds with unusual steric structures in the heavier distillates have been found to be refractory, and therefore, persistent ones. ${ }^{3}$ Consequently, there is an urgent need for the identification and quantification the 
sulfur species in order to optimize the desulfurization process and identify potential sources for environmental contamination. Alkyl benzo[b]thiophenes, dibenzo[b,d]thiophenes, benzonaphthothiophenes and phenanthro[4,5b,c,d]thiophenes are among these refractory species. ${ }^{3}$

Sulfur-containing PAH's, among them the benzo[b]naftho[2,3-d] thiophene (BNT), have been used to evaluate petroleum related environmental pollution in samples such as water, soils and sediments. In special, sediments are a good source for the evaluation of the pollution of rivers lakes and oceans since a rapid exchange of compounds can be established between the sediment placed in the bottom and the water column above it.

The determination of sulfur compounds in petroleum and derivatives and in environmental samples has been studied extensively. ${ }^{4}$ Total sulfur has been determined by a number of methods. Sulfoxide forms of sulfur are typically determined by infrared spectroscopy, aliphatic sulfides can be measured by a spectrophotometric method based on the complexation with iodine while thiols are usually determined by titration with silver nitrate. Efforts towards the isolation and the detection of specific sulfur compounds have largely utilized gas and liquid chromatographic techniques with several types of detection including flame ionization and chemiluminescence. These methods can determine most of the sulfur compounds, but require elaborate sample and data processing techniques to minimize matrix interferences and resolve signal overlaps.,

Phosphorimetry is characterized by its high sensitivity, selectivity and wide linear range. Phosphorescence can be readily obtained by using careful experimental conditions such as a de-oxigenated environment and immobilization of the analyte in order to minimize nonradiative deactivation mechanisms of the excited triplet state caused respectively by dynamic quenching and vibrational relaxation. Adsorption on a solid substrate, such as cellulose, guarantees the immobilization of several classes of analytes at room-temperature. ${ }^{7}$ The use of the external heavy-atom effect (HAE) may induce or amplify phosphorescence to a few orders of magnitude by significantly enhancing both the rate of intersystem crossing (excited singlet state - excited triplet state transition) and the phosphorescence rate constant, therefore, the detection power of room-temperature phosphorimetry is also increased. ${ }^{7,8}$ The selective nature of the HAE has made solid surface room-temperature phosphorimetry (SSRTP) an useful analytical tool for the characterization and selective determination of trace amounts of many organic compounds of interest in various types of complex samples. ${ }^{7,9}$
The purpose of this work is to demonstrate the applicability of the SSRTP for the selective determination of one specific sulfur-containing PAH (benzo[b]naphtho[2,3-d]thiophene or BNT) in a environmental sample (sediment) indicating the potential of the technique for complex samples containing several PAH's.

\section{Experimental}

\section{Apparatus}

Phosphorescence measurements were performed on a luminescence spectrometer Perkin-Elmer LS-55 (PerkinElmer, USA) coupled to a solid surface analysis apparatus modified to allow a flow of purging gas (dry nitrogen) on the sample holder. A delay time of $0.1 \mathrm{~ms}$ and a gate time of $9 \mathrm{~ms}$ were employed and found to complete eliminate second order scattering as observed by the scanning of the blanks. The nitrogen gas was dried by passing it through a silica gel bed. A laboratory made photochemical reactor, described elsewhere, ${ }^{10}$ was employed to treat the paper substrates in order to reduce background. An ultrasonic bath (CTA USB 24, SP, Brazil) was also used.

\section{Reagents}

All experiments were performed with analytical grade chemicals and ultrapure water. Whatman No. 42 filter paper was used as solid substrate. Benzo[b]naphtho[2,3d] thiophene (BNT), dibenzothiophene (DBT), carbazole and $\mathrm{TlNO}_{3}$ were purchased from Acros Organics (USA), Pyrene, 7,9-dimethylbenz[c]acridine and chrysene were from Sigma (USA). Ethanol, KI, sodium dodecyl sulfate (SDS) were obtained from Merck (Brazil), AgNO, $\mathrm{Hg}_{2} \mathrm{Cl}_{2}$ and $\mathrm{Pb}\left(\mathrm{NO}_{3}\right)_{2}$ were from VETEC (Brazil). Reference material IAEA 417 (organochlorine compounds and petroleum hydrocarbons in sediment sample) was acquired from International Atomic European Agency (Austria).

\section{Standards and solutions}

A $1 \times 10^{-3} \mathrm{~mol} \mathrm{~L}^{-1}$ stock solution of BNT was prepared in ethanol and used to prepare more diluted standard working solutions. This stock standard solution of BNT was stable for at least one week when stored away from light under refrigeration $\left(5^{\circ} \mathrm{C}\right)$. The dilute standard working solutions of BNT were stable for at least one day at room temperature. The stock solutions of SDS $\left(0.25 \mathrm{~mol} \mathrm{~L}^{-1}\right)$ and heavy atom ions $\left(0.25 \mathrm{~mol} \mathrm{~L}^{-1}\right.$ of $\mathrm{TINO}_{3}, 1.0 \mathrm{~mol} \mathrm{~L}^{-1}$ of $\mathrm{KI}, 0.5 \mathrm{~mol} \mathrm{~L}^{-1}$ of $\mathrm{AgNO}_{3}, 0.2 \mathrm{~mol} \mathrm{~L}^{-1}$ of $\mathrm{HgCl}_{2}$ and $0.5 \mathrm{~mol} \mathrm{~L}^{-1}$ of $\mathrm{Pb}\left(\mathrm{NO}_{3}\right)_{2}$ ) were prepared in water and used to prepare more diluted 
solutions. The recommended sample amount for sediment analysis is $2 \mathrm{~g}$. The material should be stored in the dark and kept in a refrigerator. The sediment sample was prepared by the extraction of a known portion of the material (approximately $2 \mathrm{~g}$ ) with $6 \mathrm{~mL}$ dichloromethane:ethanol (2:1, $\mathrm{v} / \mathrm{v})$ mixture. An amount of $100 \mathrm{mg}$ of the extract was dissolved with ethanol in order to get a $10 \mathrm{~mL}$ solution. This solution was spiked with BNT in order to get a $2.5 \times 10^{-5}$ mol L ${ }^{-1}$ final concentration. In such condition, $24 \mathrm{ng}$ of BNT is present in the substrate together with other $\mathrm{PAH}^{\text {'s }} \mathrm{s}$ (Benzo[e]pyrene, benzo[a]phenanthrene, benzo[b]fluoranthene, pyrene, chrysene and phenanthrene) in a similar mass range of 15 to $40 \mathrm{ng}$.

\section{Procedures}

Substrate (filter paper) background reduction has been described in detail elsewhere. ${ }^{11}$ This procedure basically consists of washing paper strips with boiling water in a Soxhlet apparatus for $2 \mathrm{~h}$. After dried under an infrared lamp, the paper was exposed to ultraviolet irradiation for another $2 \mathrm{~h}$. These solid substrates were cut in circles $(0.74 \mathrm{~cm}$ in diameter) to be used during the analysis. Each of all employed solutions (the following order was used: $5 \mu \mathrm{L}$ of SDS, $5 \mu \mathrm{L}$ of heavy atom solution and $5 \mu \mathrm{L}$ of the analyte solution) was spotted on the center of the solid substrates using a microliter pipette. The spotted substrates were vacuum-dried at room temperature for $2 \mathrm{~h}$ and were then placed in a desiccator until the measurements were carried out. The desiccator was covered with aluminium foil to shield substrates from ambient light. In order to make the analytical measurement, these circles were placed on a clean sample holder. Sample compartment was continuously purged with dry nitrogen gas for $3 \mathrm{~min}$ prior to each measurement.

\section{Results and Discussion}

Room-temperature phosphorescence of BNT on cellulose substrate

Room-temperature phosphorescence (RTP) characteristics of BNT, in low background filter paper, were studied in different experimental conditions. Changes of the $\mathrm{pH}$ of the analyte solutions were not performed since BNT did not dissolve in basic and acid media. Different heavy atoms salts were tested in the substrate in order to find a suitable phosphorescence enhancer for BNT. Table 1 shows the net phosphorescence as well as the maximum excitation and emission wavelengths $\left(\lambda_{\text {exc }} / \lambda_{\text {em }}\right)$ for $59 \mathrm{ng}$ of BNT $\left(5 \mu \mathrm{L}\right.$ of a $5 \times 10^{-5} \mathrm{~mol} \mathrm{~L}^{-1}$ analyte solution) deposited on the paper substrate. In the absence of heavy atom (HA), a phosphorescence signal (69 arbitrary units of RTP) was observed at 274/562 nm. However, when lead(II), silver(I) and thallium(I) were present, enhancements in signal of respectively 1.6, 2.3 and 4.1 times were observed with small shifts in the $\lambda_{\text {exc }} / \lambda_{\text {em }}$. For iodine, no phosphorescence enhancement was observed while for mercury(II), the original BNT signal was quenched (Table 1). The signal obtained with $\mathrm{Tl}(\mathrm{I})$ was further increased by applying the surfactant sodium dodecyl sulfate (SDS) in the paper substrate. In this case, the BNT signal was 7.6 times more intense than the original one in the absence of HA (Table 1). Such RTP improvements caused by the simultaneous use of HA and SDS have been reported in the literature and used to improve detection power of phosphorimetric methods. ${ }^{12,13}$ SDS is known to improve the interaction between the analyte and the heavy atom enhancer and to avoid the penetration of the analyte into the deep layers of the substrate where it cannot be interrogated by the excitation radiation. ${ }^{12} \mathrm{As} \mathrm{Pb}$ (II) is a less common phosphorescence enhancer, this heavy atom was also considered since it can be useful in terms of the analysis of a complex sample. Although generating a stronger phosphorescence than the one observed with $\mathrm{Pb}(\mathrm{II})$, the experimental condition using $\mathrm{Ag}(\mathrm{I})$ was not considered because of the high RTP standard deviation observed due probably to the dark silver oxide layer that forms on the surface of the substrate.

Room-temperature phosphorescence spectra from BNT adsorbed on filter paper in absence and in the presence of $\mathrm{TlNO}_{3} / \mathrm{SDS}$ and in the presence of $\mathrm{Pb}\left(\mathrm{NO}_{3}\right)_{2}$ are shown in Figure 1A. Total phosphorescence emission spectrum of BNT using SDS/TINO 3 was also obtained from sequential RTP scanning using a $10 \mathrm{~nm}$ increasing

Table 1. Effect of several heavy atom salts ${ }^{\mathrm{a}}$ on the phosphoresce of BNT $\left(5 \times 10^{-5} \mathrm{~mol} \mathrm{~L}^{-1}\right)$ in the low background paper substrate with or without SDS 0.07 mol L-1

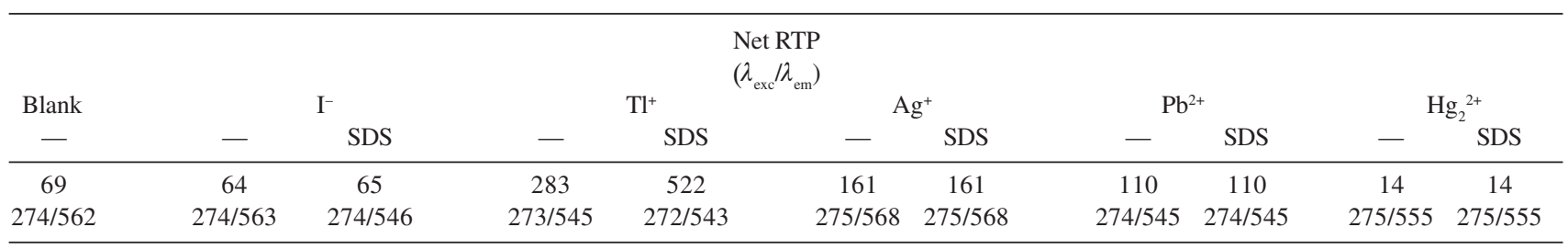

aHeavy atom solutions: $\mathrm{KI}_{1} .0 \mathrm{~mol} \mathrm{~L}^{-1}, \mathrm{TINO}_{3} 0.1 \mathrm{~mol} \mathrm{~L}^{-1}, \mathrm{AgNO}_{3} 0.5 \mathrm{~mol} \mathrm{~L}^{-1}, \mathrm{~Pb}\left(\mathrm{NO}_{3}\right)_{2} 0.5 \mathrm{~mol} \mathrm{~L}^{-1}, \mathrm{Hg}_{2} \mathrm{Cl}_{2} 0.2 \mathrm{~mol} \mathrm{~L}^{-1}$. 




$\mathbf{B}$

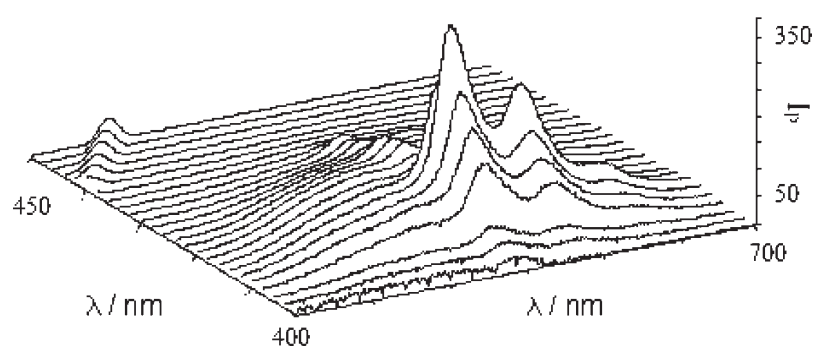

Figure 1. (A) Room-temperature phosphorescence excitation and emission spectra of $5 \times 10^{-5} \mathrm{~mol} \mathrm{~L}^{-1} \mathrm{BNT}$ adsorbed on filter paper in the absence of $\mathrm{HA}(\mathrm{a})$, in the presence of $\mathrm{SDS} / \mathrm{Pb}\left(\mathrm{NO}_{3}\right)_{2}$ (b) , in the presence of SDS/ $\mathrm{TINO}_{3}$ (c) and (B) Projection surface obtained from a total phosphorescence spectrum of a $5 \times 10^{-5} \mathrm{~mol} \mathrm{~L}^{-1} \mathrm{BNT}$ in the presence of SDS/TINO .

step. This projection is shown in Figure $1 \mathrm{~B}$ and can be used as fingerprint for a qualitative identification of BNT in a sample. A similar total phosphorescence spectrum can also be achieved using $\mathrm{Pb}(\mathrm{II})$.

\section{Maximization of BNT RTP signal}

Heavy atom enhancements can be maximized by adjusting the amount of HA in the paper substrates. In addition, the optimization of the amount of SDS is also important since the signal increasing caused by the surface modifier depends on its amount present in the substrate..$^{6,13}$ The optimization of SDS concentration is important since lower concentrations of SDS could not properly impede the migration of phosphors into the internal layers of the cellulose substrate, nor could create conditions of a better approximation between the phosphor and the heavy atom enhancer. ${ }^{12}$ On the other hand, if SDS is present in excess on the matrix, a filter effect may arise, which could block part of the phosphors from the excitation radiation. ${ }^{13}$

In this section we describe several optimizations performed to maximize the phosphorescence signals. First, the amount of SDS was optimized by using paper substrates previously spotted with $5 \mu \mathrm{L}$ of SDS solutions varying from 0 to $0.25 \mathrm{~mol} \mathrm{~L}^{-1}$. The amounts of BNT and
$\mathrm{TINO}_{3}$ were fixed at $59 \mathrm{ng}$ and $0.33 \mathrm{mg}(5 \mu \mathrm{L}$ of a 0.25 mol L-1 $\mathrm{TlNO}_{3}$ solution) respectively. It was observed that the signal improvement is already achieved with a 0.01 mol L-1 SDS solution. A decrease of signal was observed using solution with concentration above $0.05 \mathrm{~mol} \mathrm{~L}^{-1}$. The $0.01 \mathrm{~mol} \mathrm{~L}^{-1} \mathrm{SDS}$ solution was selected (Figure 2A).

In order to optimize the amount of $\mathrm{TINO}_{3}$ deposited in the substrate, a single $5 \mu \mathrm{L}$ volume approach was adopted for the deposition of the solution on the substrate. Multiple amounts or higher volumes were not used in order to avoid the spreading of the solutions in the substrate surface and therefore increasing the analyte signal variation due the lack of control of the $\mathrm{Tl}(\mathrm{I})$ present in the center of the substrate (excitation radiation target). Amounts between 0.01 to $0.33 \mathrm{mg}$ of $\mathrm{TINO}_{3}$ were used. Because of limitations on the solubility of the salt, higher amounts of $\mathrm{TlNO}_{3}$ were not tested (the most concentrated $\mathrm{TINO}_{3}$ solution was $0.25 \mathrm{~mol} \mathrm{~L}^{-1}$ ). It is observed that the larger amount of $\mathrm{Tl}(\mathrm{I})$ was responsible for the highest signal. Therefore, a $0.25 \mathrm{~mol} \mathrm{~L}^{-1} \mathrm{TINO}_{3}$ solution $(0.33$ $\mathrm{mg}$ of the salt) was selected to spot the substrate (Figure 2B).

The alternative experimental condition using $\mathrm{Pb}$ (II) was also optimized. Although, SDS was found to improve RTP from BNT in the presence o $\mathrm{Pb}(\mathrm{II})$, a study using other amounts of SDS was performed. This optimization indicated that best concentration of SDS to be used in the substrate is $0.07 \mathrm{~mol} \mathrm{~L}^{-1}$ (Figure 2C). The amount of $\mathrm{PbNO}_{3}$ was also varied between 0.16 to $0.83 \mathrm{mg}$. The 0.41 $\mathrm{mg}$ of $\mathrm{Pb}(\mathrm{NO})_{3}$, obtained from $5 \mu \mathrm{L}$ of a $0.25 \mathrm{~mol} \mathrm{~L}^{-1}$ $\mathrm{Pb}\left(\mathrm{NO}_{3}\right)_{2}$ solution, was found to induce the strongest RTP (Figure 2D).

\section{Analytical figures of merit}

The analytical figures of merit were obtained under the experimental conditions optimized for the two RTP experimental conditions. In the case of $\mathrm{TINO}_{3} / \mathrm{SDS}$, the analytical curve showed a linear dynamic range that extended over three orders of magnitude (from 2 to 1170 ng of analyte in the substrate). Correlation coefficient of the analytical curve was close to unity (0.9911). The standard deviation for 16 blank repetitions was around $13 \%$, which can be considered satisfactory for analytical techniques based on measurements on a solid substrate. The absolute limit of detection (ALOD) of $0.6 \mathrm{ng}$ was estimated. ALOD was calculated based on the following equation: $3 \mathrm{~s}_{\mathrm{b}} \mathrm{m}^{-1} \mathrm{~V}$ MM, where $\mathrm{s}_{\mathrm{b}}$ is the standard deviation from 16 blank determinations, $\mathrm{m}$ is the slope of the analytical curve, MM is the molar mass of BNT and V is the analyte volume deposited on the substrate $(5 \mu \mathrm{L})$. The 

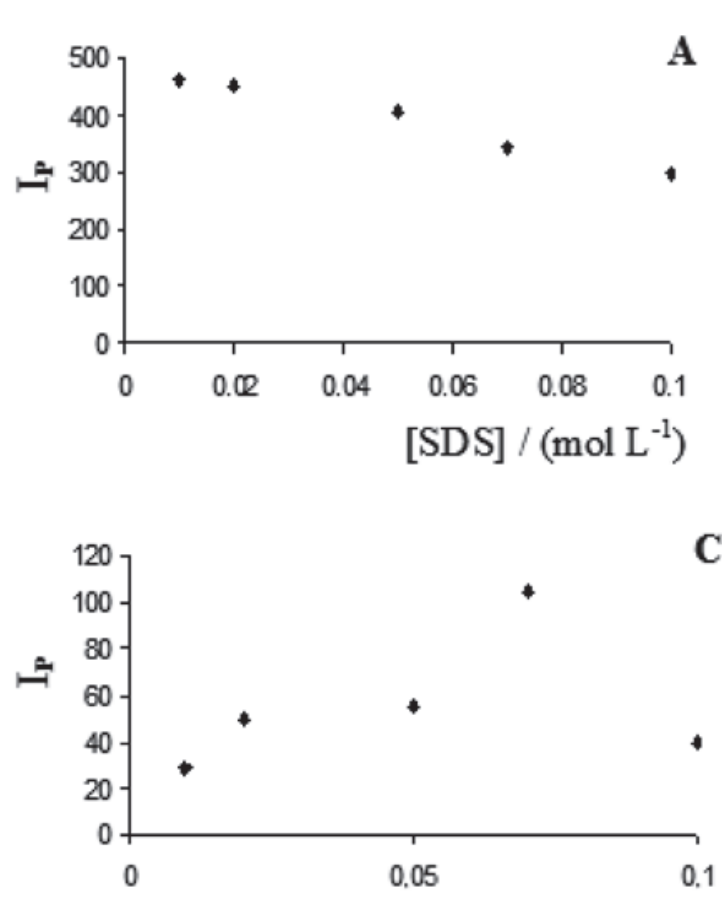

$[\mathrm{SDS}] /\left(\mathrm{mol} \mathrm{L}^{-1}\right)$

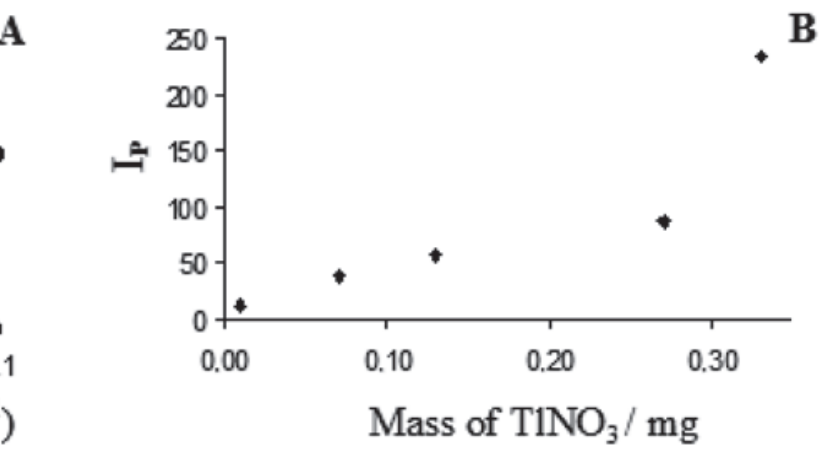

B

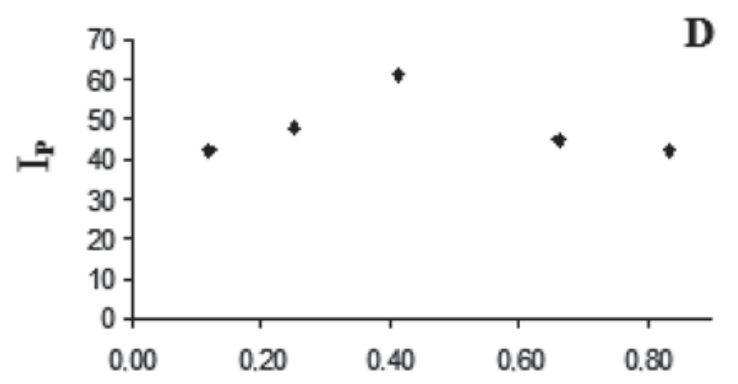

Mass of $\mathrm{Pb}\left(\mathrm{NO}_{3}\right)_{2} / \mathrm{mg}$

Figure 2. (A) Experimental optimizations using $59 \mathrm{ng}$ BNT: surfactant concentration in the presence of $\mathrm{TINO}_{3}(\mathrm{~A})$; mass of TINO $(\mathrm{B})$; surfactant concentration in the presence of $\mathrm{Pb}\left(\mathrm{NO}_{3}\right)_{2}(\mathrm{C})$; and mass of $\mathrm{Pb}\left(\mathrm{NO}_{3}\right)_{2}$ (D). Optimized Gate Time and Delay Time conditions are 9 ms and $0.1 \mathrm{~ms}$ respectively.

theoretical minimum mass of analyte that can be detected by this SSRTP method was $2 \mathrm{ng}$. This value was calculated using the absolute limit of quantification (ALOQ) based on the $10 \mathrm{~s}_{\mathrm{b}} \mathrm{m}^{-1} \mathrm{~V}$ MM criteria.

When $\mathrm{SDS} / \mathrm{Pb}\left(\mathrm{NO}_{3}\right)_{2}$ was used as phosphorescence enhancer, the analytical figures of merit were $3.2 \mathrm{ng}$ (ALOD) and $10.7 \mathrm{ng}$ (ALOQ). Correlation coefficient of the analytical curve was close to unity (0.9961) with a range that extended over three orders of magnitude (from 10.7 to $1170 \mathrm{ng}$ of analyte in the substrate). The standard deviation for 16 blank repetitions was $11 \%$.

\section{RTP determination of BNT in a reference sediment sample}

The SSRTP method was tested using a sediment reference material containing several PAH's. The sediment extract was diluted and then spiked with a known amount of BNT in order to allow a recovery test to be made. The observation of RTP from BNT directly from the sediment extract deposited on the substrate was not possible because of non-spectral interferences imposed by the matrix (internal filter effect). Such type of interferences is minimized as the sample is diluted before deposition on the substrate. The dilution factor chosen was one that totally eliminated non-spectral interferences from the matrix, allowing the quantification of BNT using the analyte curve. Nevertheless, the analyte addition method could be employed for less diluted samples.

In order to choose the experimental condition to analyze the sediment sample, the selectivity was taking into consideration. $\mathrm{Tl}(\mathrm{I})$ is a very common RTP inducer for several PAH's and other classes of organic compounds, ${ }^{6}$ and therefore, not indicated for the analysis of such kind of complex sample. The $\mathrm{Pb}\left(\mathrm{NO}_{3}\right)_{2} / \mathrm{SDS}$ was then chosen because of its more selective nature as a RTP inducer, as it was demonstrated in Figure 3, where the RTP spectrum of the non-spiked sediment is similar to the background signal from the cellulose substrate in the presence of $\mathrm{Pb}\left(\mathrm{NO}_{3}\right)_{2} / \mathrm{SDS}$ under the optimized conditions. From Figure 3 it is also observed that when signal measurement is made at $593 \mathrm{~nm}$, a smaller background environment is achieved, improving detection power of the method. This result clearly shows that BNT could be selectively determined, even in a complex sediment sample, by using $\mathrm{Pb}(\mathrm{II})$ as the heavy atom inducer.

The BNT was determined in the sediment extract using the analytical curve procedure and six determinations were performed. Paper substrates impregnated with SDS and $\mathrm{Pb}\left(\mathrm{NO}_{3}\right)_{2}$ were used as blanks. The spiked amount of BNT was recovered with an average value of $101.5 \pm 7.4 \%$. Room-temperature phosphorescence spectra from BNTspiked sediment adsorbed on filter paper in the presence 


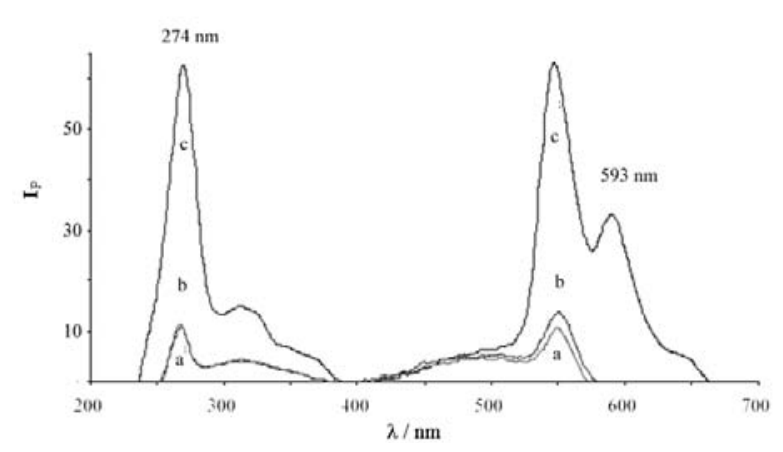

Figure 3. Excitation and emission RTP using filter-paper substrate in the presence of $\mathrm{Pb}\left(\mathrm{NO}_{3}\right)_{2} / \mathrm{SDS}$ (a), non-spiked sediment extract in the presence of $\mathrm{Pb}\left(\mathrm{NO}_{3}\right)_{2} / \mathrm{SDS}$ (b) and of BNT-spiked sediment in the presence of $\mathrm{Pb}\left(\mathrm{NO}_{3}\right)_{2} / \mathrm{SDS}(\mathrm{c})$. Determination made at $\lambda_{\mathrm{exc}} / \lambda_{\mathrm{em}}=274 / 593 \mathrm{~nm}$.

of $\mathrm{Pb}\left(\mathrm{NO}_{3}\right)_{2} / \mathrm{SDS}$ are shown in Figure 3. This result confirmed the potential of SSRTP for the selective determination of BNT in a complex sediment sample containing several concomitant substances.

A few specific substances were studied in order to understand such selective nature of the SSRTP method for BNT. The potential interference of one sulfurcontaining PAH (dibenzothiophene, DBT) in the phosphorescence signal of BNT was evaluated. Using the experimental conditions optimized for BNT, no phosphorescence was observed for DBT. Two other PAH's (pyrene and chrysene) presented phosphorescence in the presence of $\mathrm{Pb}(\mathrm{II})$, but in another spectral region which did not implicate in interferences on the BNT. Two nitrogen-containing PAH's (carbazole and 7,9dimethylbenz[c]acridine) were also evaluated and no phosphorescence was observed with $\mathrm{Pb}\left(\mathrm{NO}_{3}\right)_{2} / \mathrm{SDS}$.

\section{Conclusions}

In this work, we have reported the RTP characteristics of BNT on low-background paper substrates. Several experimental parameters that usually affect the intensity of phosphorescence emission were studied. Five salts of heavy atoms were tested as RTP enhancers. The combined use of $\mathrm{TINO}_{3}(0.33 \mathrm{mg})$ and $\mathrm{SDS}\left(5 \mu \mathrm{L}\right.$ of a $0.01 \mathrm{~mol} \mathrm{~L}^{-1}$ solution $)$ was found to be the best conditions for RTP enhancement when sensitivity is required. $\mathrm{Pb}\left(\mathrm{NO}_{3}\right)_{2}(0.41 \mathrm{ng})$ and SDS (5 $\mu \mathrm{L}$ of a $0.07 \mathrm{~mol} \mathrm{~L}^{-1}$ solution) was found to be the best conditions for the determination of BNT in sediment samples due to the selective nature of the $\mathrm{Pb}(\mathrm{II})$ induced phosphorescence. The use of the selective phosphorescence enhancement and differences in the spectral characteristics between analyte and concomitant substances in complex samples may allow selective determination without the need for previous separation procedures. ${ }^{14}$
Under these optimized instrumental and experimental conditions, the RTP method presented figures of merit appropriate for trace-level determination of BNT. Recoveries close to $100 \%$ were achieved using the analytical curve procedure.

\section{Acknowledgments}

The authors thank the Conselho National de Desenvolvimento Científico e Tecnológico-CNPq for scholarships and financial support and LABMAN (PUC$\mathrm{RJ}$ ) for the donation of the sediment sample.

\section{References}

1. Speight, J.G.; Handbook of Petroleum Analysis, Wiley: New York, 2001.

2. Balko, J.; Podratz, D.; Olesen, J.; Proceedings of the NPRA Annual Meeting, Paper AM-00 14, St Antonio, TX, 2000.

3. Ma, X.; Sakanishi, K.; Isoda, T.; Mochida, I.; Fuel 1997, 76, 329.

4. Nishioka, M.; Campbell, R. M.; Lee, M. L.; Castle, R. N.; Fuel 1986, 65, 270.

5. Green, J. B.; Yu, S. K. T.; Pearson, C. D.; Reynolds, J. W.; Energy Fuels 1993, 7, 119.

6. Vo-Dinh, T.; Chemical Analysis of Polycyclic Aromatic Compounds (Chemical Analysis: A Series of Monographs on Analytical Chemistry and Its Applications), Wiley: New York, 1989, vol. 101.

7. Vo-Dinh, T.; Room Temperature Phosphorimetry for Chemical Analysis, (Chemical Analysis: A Series of Monographs on Analytical Chemistry and Its Applications), Wiley: New York, 1984, vol. 68 .

8. Kasha, M.; J. Chem. Phys. 1952, 20, 71.

9. Hurtubise R.J.; Phosphorimetry: Theory, Instrumentation and Applications, VCH: New York, 1990.

10. Cardoso, C. E.; Martins, R. O. R.; Telles, C. A. S.; Aucélio, R. Q.; Microchim. Acta 2004, 146, 79.

11. Cardoso, C. E.; Martins, R. O. R.; Aucélio, R. Q.; Abstracts of the $27^{a}$ Reunião Anual da Sociedade Brasileira de Química and XXVI Congresso Latino-americano de Química, Salvador, Brazil, 2004.

12. De Lima, C. G.; Andino, M. M.; Winefordner, J. D.; Anal. Chem. 1986, 58, 2867.

13. Aucélio, R. Q.; Campiglia, A. D.; Anal. Chim. Acta 1995, 309, 345.

14. Vo-Dinh, T.; Hooyman, J. R.; Anal. Chem. 1979, 51, 1915.

Received: February 19, 2006

Published on the web: September 13, 2006 